\title{
Teologia contextual: cristianismo e cultura no fazer teológico africano a partir da Declaração de Acra, Gana, de 1977
}

\author{
Júlio Macuva Estendar* \\ Vitor Chaves de Souza**
}

\section{Resumo}

O artigo apresenta e atualiza o tema da teologia africana subsaariana para a discussão teológica atual. Para tal tarefa, a partir do estudo sociológico de Peter Berger e dos documentos da declaração de Acra, Gana, de 1977, pretende-se explorar a relação da cultura com a religião típica da África. O exercício é feito, também, com o aporte teórico de Paul Tillich e a sua célebre intuição, "a religião é a substância da cultura e a cultura é a forma da religião". Ao se voltar para a situação concreta das comunidades do continente africano e questionar o processo de colonização, pode-se afirmar que o cristianismo, como religião fundante do ocidente, configura-se como substância da cultura das comunidades cristãs africanas e a cultura africana dessas comunidades confere forma ao cristianismo no continente. Assim sendo, o artigo discorre a respeito das características da teologia contextual africana e valoriza as suas reflexões originais.

Palavras-chave: Teologia contextual. Teologia africana. Cultura. Religião. África subsaariana.

\section{Contextual theology: christianity and culture in the African Theological Making From The Accra Declaration, Ghana, 1977}

\footnotetext{
Abstract

The article presents and modernizes the sub-Saharan African theology for the current theological discussion. For this task, having Peter Berger's sociological references and

* Bacharel em Teologia e Especialista em Filosofia e Teologia Contemporânea pela Faculdade Nazarena do Brasil, e mestrando em Ciências da Religião pela Universidade Metodista de São Paulo.

** Doutor em Ciências da Religião e professor na Faculdade de Filosofia e na Pós-Graduação em Ciências da Religião da Universidade Metodista de São Paulo.
} 
the Accra Declaration documents, Ghana, 1977, we intend to explore the typical African relationship between culture and religion. We also refer to the theoretical contribution of Paul Tillich and his famous intuition, "religion is the substance of culture, and culture is the form of religion". Questioning the process of colonization and according to the concrete situation of African communities, one can affirm that Christianity, as the founding religion of the West, is the substance of African communities' culture and the African culture shapes Christianity on the continent. Thus, the article discusses the characteristics of African contextual theology and its original thoughts.

Keywords: Contextual theology. African theology. Culture. Religion. Sub-Saharan Africa.

\section{Teología contextual: cristianismo y cultura en el hacer teológico africano a partir de la Declaración de Accra, Ghana, de 1977}

\section{Resumen}

El artículo presenta y actualiza el tema de la teología africana subsahariana para la discusión teológica actual. Para tal tarea, a partir del estudio sociológico de Peter Berger y de los documentos de la declaración de Accra, Ghana, de 1977, se pretende explorar la relación de la cultura con la religión típica de África. El ejercicio se hace, también, con el aporte teórico de Paul Tillich y su célebre intuición, "la religión es la sustancia de la cultura y la cultura es la forma de la religión". Al volver a la situación concreta de las comunidades del continente africano y cuestionar el proceso de colonización, se puede afirmar que el cristianismo, como religión fundadora del occidente, se configura como sustancia de la cultura de las comunidades cristianas africanas y la cultura africana de estas comunidades confiere forma al cristianismo en el continente. Así, el artículo discurre sobre las características de la teología contextual africana y valora sus reflexiones originales.

Palabras clave: Teología contextual. Teología africana. La cultura. La religión. África subsahariana.

\section{Introdução}

Este texto pretende explorar as questões ligadas à relação que a religião mantém com a cultura. Para isso, analisamos o caso específico da teologia africana, pois ela comunga elementos culturais africanos nas suas abordagens teológicas no contexto específico do continente. Inicialmente, analisaremos as contribuições dos autores Peter Berger (1985) e Paul Tillich (2009) acerca das questões voltadas para a temática da relação entre religião e cultura. Tais contribuições nos permitirão fundamentação teórica sobre a temática. No segundo momento, voltamo-nos à análise do caso concreto da teologia africana: uma vez que a proposta teológica se faz a partir da relação entre a religião (cristianismo) e a cultura africana, nesta seção vemos os dois 
elementos em uma relação indissolúvel. Tal como apresentado por Tillich em sua obra Teologia da Cultura, pode-se afirmar que o cristianismo, como religião fundante do ocidente, se configura como substância da cultura das comunidades cristãs africanas e a cultura africana destas comunidades confere forma ao cristianismo no continente. Pois, para o autor, a religião é substância da cultura e a cultura, por sua vez, é a forma pela qual a religião se mostra em seu modo mais elevado. "A religião é substância, o fundamento e a profundidade da vida espiritual dos seres humanos" (TILLICH, 2009, p. 45). A metáfora da profundida apresenta-se como uma chave de leitura das produções e interações dos domínios religiosos e culturais, sobretudo na preocupação última (ultimate concern) e a seriedade incondicional que essa esfera exige. Peter Berger, com semelhante motivação e método inovador, percebe a interação entre religião e cultura como o ato responsável pela cosmificação do mundo da humanidade. É nesse sentido que a relação entre as duas é fundamentada para um desdobramento singular da religiosidade africana a partir da declaração de Acra, Gana, de 1977.

\section{A relação entre teologia e cultura: questões introdutórias}

Para trabalhar as questões da relação entre teologia e cultura, partimos da análise de conceitos mais abrangentes e orbitados em torno da temática da cultura e das aproximações com o campo da religião. Para isso, o trabalho O Dossel Sagrado, de Peter Berger, exibe a fundamentação de um método social com incidência fenomenológica propícia para a questão da relação entre religião e cultura a partir de uma sociologia da religião. Após Berger, o teólogo e filósofo alemão Paul Tillich, cuja obra central Teologia da Cultura se apresenta necessária, faz uma abordagem teológico-filosófica ecoando preocupações ontológicas para um tema - religião e cultura - cuja faceta é dupla: pode ser visto tanto sociologicamente quanto filosoficamente. Cada um desses autores trabalha a temática atendendo a perspectivas epistemológicas e metodológicas diferentes, afinal seus lugares de fala são perpassados por escopos teóricos próprios e, de certo modo, refletem a particularidade de cada mundo expressado em seus textos.

O presente artigo passa de uma questão mais geral - primeiro aspecto da generalidade do círculo hermenêutico - para a análise de uma proposição particular - o aspecto subsequente do específico do círculo hermenêutico -, ou seja, parte-se da observação das questões da relação religião e cultura 
como temática maior de uma área vindoura das ciências humanas e sociais e, num segundo momento, volta-se para o caso específico, a particularidade, da relação da teologia cristã africana com a cultura onde é proficuamente gestada em seus textos fundantes.

\subsection{A religião e a construção do mundo: análise da relação entre religião e cultura a partir das contribuições de Peter Berger}

Em seu livro O Dossel Sagrado: elementos para uma teoria sociológica da religião, Berger propõe trabalhar a compreensão da religião como produto histórico (1985, p. 10) segundo uma tarefa de elaboração sociológica, na qual seu empreendimento teórico é perpassado pelo escopo metodológico próprio da disciplina. A premissa essencial de seu texto reside, a despeito de uma concepção convencional do fenômeno religioso, numa análise da sociedade humana cujo empreendimento de construção de mundo oferece à religião uma ocupação privilegiada e elevada na estrutura social da construção do mundo. O principal objetivo do autor, portanto, é o de levantar alguns enunciados no que se refere à relação entre a religião e a construção do mundo via processos sociais (BERGER, 1985, p. 15).

Berger concebe a sociedade como um produto da criação humana. Ela se apresenta a partir de um fenômeno originariamente dialético. $\mathrm{O}$ autor idealiza, aqui, o conceito dialético a partir do arcabouço teórico da disceptação marxista, mesmo não se preocupando em alongar o referencial de geral dos termos. Por sua vez, a sociedade não existiria sem a presença humana, pois ela é fruto da concepção humana. No entanto, a afirmação remete a outra afirmação, em que o homem, em sua condição social, é ele próprio também um produto da sociedade. Berger afirma:

Toda biografia individual é um episódio dentro da história da sociedade, que a precede e lhe sobrevive. A sociedade existia antes que o indivíduo nascesse, e continuará a existir após a sua morte. Mais ainda, é dentro da sociedade, como resultado de processos sociais, que o indivíduo se torna uma pessoa, que ele atinge uma personalidade e se aferra a ela, e que ele leva adiante os vários projetos que constituem a sua vida. O homem não pode existir independentemente da sociedade. As duas asserções, a de que a sociedade é produto do homem e a de que o homem é produto da sociedade, não se contradizem (BERGER, 1985, p. 15). 
O ser humano não existe sem a sociedade e esta não existe sem a humanidade. Uma complementa a outra em sua existência no seio da realidade histórica, formando o processo civilizatório de determinada sociedade. A natureza da experiência humana mediada pela sociedade, dessa forma, permite à sociedade trazer a existência do mundo humano na particularidade do mundo natural. Do mesmo modo, a sociedade se torna fruto dos processos criacionais do mundo humano a despeito da anterioridade dos processos de ordem natural na ordem da cadeia biológica. Assim, a construção do mundo fornece à vida humana as estruturas firmes que lhe faltam biologicamente (BERGER, 1985, p. 19).

Dito isso, o autor apresenta três momentos decisivos para a abordagem sociológica em seu escopo dialético fundamental à sociedade. Estes momentos são: a exteriorização, a objetivação e a interiorização. No primeiro momento, a exteriorização, trata-se de um ato contínuo e criativo de lançar-se sobre o mundo. Tal movimento se dá nas atividades físicas ou mentais desenvolvidas pelos humanos no seu encontro com a realidade externa a eles, i. e., o mundo par excellence. ${ }^{1} \mathrm{O}$ segundo momento, a objetivação, promove a apropriação das partes dos produtos das atividades físicas e mentais de uma realidade constantemente defrontante dos seus produtores (com facticidade exterior e distinta deles). Aqui se observam os produtos das atividades físicas e mentais ao se encontrarem num mundo independente dos seus produtores originais, pois entes, afinal, encontram-se constantemente em estados de transmutações. Por último há a interiorização, que se configura na reapropriação dessa mesma realidade por parte do ser humano. No entanto, surge um novo processo, que transforma as estruturas do mundo objetivo concreto em estruturas da consciência subjetiva. Para efeito de introdução, é importante frisar que tais momentos dialéticos são essenciais no processo de gênese de toda e qualquer sociedade humana (BERGER, 1985).

Em seu texto, Berger sintetiza os três momentos dialéticos da sociedade e formula a síntese, ainda que provisoriamente em virtude do trabalho pretendido, da seguinte maneira: "É através da exteriorização que a sociedade é um produto humano. É através da objetivação que a sociedade se torna uma realidade sui generis. É através da interiorização que o homem é um produto da sociedade" (BERGER, 1985, p. 16).

\footnotetext{
Vale notar que o termo mundo é entendido por Berger num sentido fenomenológico - direção na qual será possível cruzar a pesquisa sociológica de Berger com as análises filosóficas de Paul Tillich.
} 
O mundo humano se apresenta em constante construção. Para restringir no texto do contexto do autor, o mundo humano é imperfeitamente programado pela própria constituição. $\mathrm{O}$ mundo é aberto e anelante por ser modelado, constantemente, pelas atividades, físicas e mentais, que permeiam a existência humana. O mundo humano é, antes de tudo, o sistema mediador excepcional entre o homem e a natureza, afinal a experiência deste é mediada pelos sistemas por ele criados. Podemos afirmar que o mundo humano não é hereditário, mas, sim, adquirido, pois a relação com o mundo é estabelecida continuamente em atos humanos. Berger assim descreve este movimento:

O homem não possui uma relação preestabelecida com o mundo. Precisa estabelecer continuamente uma relação com ele. A mesma instabilidade assinala a relação do homem com seu próprio corpo. De um modo curioso, o homem está "fora de equilíbrio" consigo mesmo. Não pode descansar em si mesmo, e para entrar em harmonia consigo mesmo precisa exprimir-se continuamente em atividade. A existência humana é um contínuo "pôr-se em equilíbrio" do homem com seu corpo, do homem com o seu mundo. Outro modo de exprimir isto é dizer que o homem está constantemente no processo de "pôr-se em dia consigo mesmo". É nesse processo que o homem produz um mundo. Só um mundo assim, que ele mesmo produziu, pode estabelecerse e realizar a sua vida (BERGER, 1985, p. 18).

O que é o mundo do homem para Berger? A despeito de o mundo, enquanto horizonte para a fenomenologia, o autor entende que este mundo naturalmente é a cultura, pois ela é responsável por fornecer à vida humana as estruturas firmes para lidar com a natureza. É justamente nesse aspecto que surge a interação da fenomenologia com a sociologia, uma vez que o mundo é o espaço vivencial do modo do ser. O lugar próprio do modo do ser é a cultura. Dessa forma, Berger descreve que para o homem a cultura se apresenta como uma "segunda natureza", uma vez que esta é completamente diferente da natureza. A cultura é produto da atividade humana, pura criação do homem. Como produto, a cultura pode ser subdividida em material ou não; assim, as sociedades humanas podem ser enquadradas na cultura não material. Nosso autor assevera: "como apenas um elemento da cultura, a sociedade compartilha do caráter desta como produto humano. A sociedade é constituída e mantida por seres humanos em ação. Não possui ser algum, realidade alguma, independentemente de tal atividade" (BERGER, 1985, p. 20). No entanto, a sociedade, como um dos aspectos da cultura, ocupa uma 
posição privilegiada entre os outros produtos culturais humanos, pois ela se insere na necessidade básica da sociabilidade do homem (BERGER, 1985).

É trabalhando juntos que os homens fabricam instrumentos, inventam línguas, aderem a valores, concebem instituições, e assim por diante. A participação individual numa cultura não só acontece num processo social (a saber, o processo chamado socialização), mas a continuação de sua existência cultural depende da manutenção de dispositivos sociais específicos. A sociedade é, portanto, não só resultado da cultura, mas uma condição necessária dela. A sociedade estrutura, distribui e coordena as atividades de construção do mundo desenvolvidas pelos homens. E só na sociedade os produtos dessas atividades podem durar (BERGER, 1985, p. 21).

A vivência em sociedade é responsável por inserir o homem no mundo. Essa inserção é a responsável, no que lhe diz respeito, por fornecer os elementos culturais necessários para o homem experienciar o mundo natural como ele se apresenta. E, na tensão dialética da existência entre mundo natural e mundo social, surge a cultura como substrato de uma relação existencial e vivencial de formas e substâncias originárias.

Depois de descrever a cultura como produto das atividades humanas e da sociedade como uma criação unicamente da cultura, Berger trabalha a questão propriamente da religião, já que, para o autor, como a cultura, a religião é também criação meramente humana ao estabelecer um cosmos sagrado. "A religião é a cosmificação feita de maneira sagrada. Por sagrado entende-se aqui uma qualidade de poder misterioso e temeroso, distinto do homem e todavia relacionado com ele, que se acredita residir em certos objetos da experiência" (BERGER, 1985, p. 38). O autor entende a religião como ordenadora do mundo humano não para esgotar a temática, mas para ampliá-la de acordo com as inúmeras culturas e a diversidade religiosa nelas inerentes, uma vez que a cultura está à disposição de qualquer um e relega radicalidade na atividade humana. Por conseguinte, a religião é, também, responsável por mediar a relação do ser humano com a natureza, organizando o espaço e o tempo do mundo em função das hierofanias. Dessa maneira, tanto a cultura como a religião são concebidas como cosmologias de ordenamento do mundo. O diferencial entre as duas acepções, a rigor, encontra-se na dialética entre o sagrado e o profano, onde a cosmologia religiosa persegue o sagrado manifesto ao invés dos elementos mundanos. Berger se faz valer das definições de dois grandes autores da filosofia e da 
história das religiões: o alemão Rudolf Otto e o romeno Mircea Eliade. Interessante destacar o solo fenomenológico dos trabalhos dos dois autores. A acepção de Berger acerca do sagrado é fruto do diálogo entre Otto e Eliade. Tanto para Otto como para Eliade, o sagrado se apresenta como toda e qualquer oposição ao profano (cf. ELIADE, 2001, p. 58). Em Otto, por sua vez, o sagrado é concebido como o totalmente outro, i.e., algo completamente contrário à realidade profana (cf. OTTO, 2007, p. 45). Por realidade profana Otto a entende como a vida cotidiana em si. Já para Eliade, apesar de não distanciar-se muito de Otto, o sagrado é tudo aquilo que não é profano: ou melhor, o profano é aquilo que está diante do sagrado. ${ }^{2} \mathrm{O}$ exemplo dado para ilustrar é a figura de uma porta no lugar sagrado: da porta para dentro se encontra o sagrado e da porta para fora se encontra o profano. A porta representa uma dinâmica existencial do sagrado onde a solução de continuidade entre o mundo profano e o mundo religioso é resolvida na medida em que há um elemento diferenciador dos dois mundos. O mundo real é vivido na esfera do sagrado (PIAZZA, 1983, p. 67).

A religião como uma cosmologia sagrada modeliza o mundo do homem. Ao fazer isso, ela permeia todas as esferas da vida humana em seu mundo ordenado. A religião, assim, perpassa certos objetos da experiência humana com o conceito da qualidade do sagrado inerente nos produtos das atividades (físicas e mentais) humanas, e alcança o seu mais elevado produto, a saber, a cultura. Berger descreve o movimento da seguinte forma:

Essa qualidade pode ser atribuída a objetos naturais e artificiais, a animais, ou a homens, ou às objetivações da cultura humana. Há rochedos sagrados, instrumentos sagrados, vacas sagradas. O chefe pode ser, sagrado, como o pode ser um costume ou instituição particular. Pode-se atribuir a mesma qualidade ao espaço e ao tempo, como nos lugares e tempos sagrados. A qualidade pode finalmente encarnar-se em seres sagrados, desde os espíritos eminentemente locais às grandes divindades cósmicas. Estas últimas podem, por sua vez, ser transformadas em forças ou princípios supremos que governam o cosmos, e não mais concebidas em termos pessoais, mas ainda investidas do status de sacralidade (BERGER, 1985, p. 39).

No trecho citado, podemos observar que o autor descreve alguns objetos materiais ou não materiais da cultura como sendo perscrutados pela religião, mas concretamente pelas qualidades do sagrado. Vemos uma relação

2 Cf. etimologia, lt. pro-fanum: aquilo que está diante da fania, i.e., diante da manifestação. 
minuciosa entre cultura e religião, pois as duas são produtos das atividades humanas e elas, à vista disso, criam e ordenam a vida do sujeito no mundo. A religião como cosmos perpassa como um fio condutor pela vida do bomo religiosus no mundo, pois entre as suas funções primordiais está a ordenação - de sentido - do mundo. O mundo natural se apresenta, antagonicamente, como um caos para o sujeito religioso, enquanto a religião e a cultura se configuram como as estruturas ordenadoras desse caos.

"O sagrado é apreendido como algo que 'salta para fora' das rotinas normais do dia a dia, como algo de extraordinário e potencialmente perigoso, embora seus perigos possam ser domesticados e sua força aproveitada para as necessidades cotidianas" (BERGER, 1985, p. 39). A qualidade do sagrado que se encontra presente no mundo do homem é ao mesmo tempo transcendente a essa realidade, ou seja, o sagrado que "salta para fora" se relaciona com esse ser humano que é marcado pela cultura. A religião cria um cosmos transcendente ao homem, mas ao mesmo tempo imanente a ele, dessa forma a religião é geradora de significados e sentidos para o mundo do homem. Berger descreve assim o papel da religião no empreendimento de construção do mundo do homem:

Pode-se dizer, portanto que a religião desempenhou uma parte estratégica no empreendimento humano de construção do mundo. A religião representa o ponto máximo da auto-exteriorização do homem pela infusão, dos seus próprios sentidos sobre a realidade. A religião supõe que a ordem humana é projetada na totalidade do ser. Ou por outra, a religião é a ousada tentativa de conceber o universo inteiro como humanamente significativo (BERGER, 1984, p. 41).

Dessarte, para Peter Berger, no grande empreendimento de construção do mundo humano, a religião e a cultura se constituem como essências e referências fundamentais de um mundo socialmente organizado e humanamente experimentado. O mundo do sujeito é uma "segunda natureza" tal qual essa é responsável por mediar a relação homem-natureza. Religião e cultura, em tensão originária, se articulam como produtos das atividades humanas, do mesmo modo que elas são responsáveis por formar o homem e introduzi-lo no mundo em alteridade. Assim, se a religião e a cultura formam cosmogonias originárias de ordenação do mundo, lhe conferindo o caráter mais humano, elas também se configuram como geradoras de significados estruturantes dessa "segunda natureza" - na qual repousam as análises além da abordagem sociológica, como as reflexões existencialistas de Paul Tillich acerca do assunto em questão. 


\subsection{Análise religiosa da cultura: contribuições a partir de Paul Tillich}

As contribuições de Paul Tillich no que se refere à relação entre religião e cultura são extraídas de seu livro Teologia da Cultura. Nessa obra, o autor propõe abordar a questão da dimensão religiosa presente nas diversas esferas da atividade cultural humana. Tillich é um autor com uma produção acadêmica prolixa e, por isso, nos limitaremos nas contribuições descritas nessa obra, uma vez que, mesmo sendo esse um de seus primeiros escritos, a temática da relação entre religião e cultura trespassa as discussões acadêmicas em outras obras do autor, inclusive sua Teologia Sistemática. Nesse sentido, ao debruçar-se sobre a dimensão religiosa da cultura, Tillich propõe um percurso de pensamento a partir de uma compreensão existencial. O autor concebe a religião em uma categoria denominada por preocupação suprema, i.e., a religião é o espaço da manifestação do sagrado que, ao invés de nominado, este é identificado com aquilo que preocupa a humanidade em última análise (TILLICH, 2009, p. 34).

A religião tem uma relação profunda com a cultura. Os intercâmbios entre ambas são constantes, fluentes e subterrâneos. A cultura como sistema organizador do mundo natural gesta a religião, enquanto que, ao mesmo tempo, a religião também se apresenta como um sistema organizador do mundo, uma fornecendo sentido a outra, de modo que, dinamicamente criativa, a religião cria a cultura. Ambas são dotadas de uma capacidade cosmológica original com formação compartilhada. A respeito de tal capacidade e relação, Tillich descreve:

A religião, considerada preocupação suprema, é a substância que dá sentido à cultura, e a cultura, por sua vez, é a totalidade das formas que expressam as preocupações básicas da religião. Em resumo: religião é a substância da cultura e a cultura é a forma da religião. Com isso evita-se o dualismo entre religião e cultura. Cada ato religioso, não apenas da religião organizada, mas também dos mais íntimos movimentos da alma, é formado culturalmente (TILLICH, 2009, p. 83).

Sendo assim, não seria possível dissociar a religião da cultura, vice-versa, pois a primeira é concebida como a substância da segunda, reciprocamente, a segunda é a totalidade das formas manifestadas à primeira. O fenômeno religioso não acontece num mundo mergulhado no caos, mas, sim, no cosmos, com a ordenação do mundo. Tanto a religião como a cultura 
são partícipes e se realizam mutuamente. Há, segundo Paul Tillich, um fundo comum - a linguagem - de onde a religião, enquanto substância, e a cultura, enquanto forma, se encontram para a transformação da sociedade.

Esta afirmação é provada pelo fato de que todos os atos da vida espiritual humana realizam-se por meio de linguagem falada ou silenciosa. A linguagem é a criação cultural básica. Por outro lado, não existe criação cultural que não expresse a preocupação suprema. É o que se vê nas funções teóricas da vida espiritual como, por exemplo, na instituição artística e na recepção cognitiva da realidade; também nas funções práticas como, por exemplo, na transformação pessoal e social da realidade. A preocupação suprema está presente em todas essas funções. Sua expressão imediata é o estilo da cultura. Quem conseguir ler esse estilo pode descobrir a preocupação suprema, sua substância religiosa (TILLICH, 2009, p. 84).

A religião encontra na cultura o cenário perfeito para a sua manifestação. A cultura é um sistema de normas que fazem a mediação entre humanidade e o mundo natural, é nesse sistema de mediações que o fenômeno religioso é vivenciado. Pode-se concluir esta seção com a indicação da relação entre religião e cultura e suas características cosmogônicas fundantes de uma premissa de ordenação do mundo do homem. A relação entre ambas gera olhares novos e diferenciados sobre o mundo natural. Tanto a religião como a cultura fornecem elementos de cosmificação do mundo. O diferencial se encontra na sacralização do mundo: a cultura cria um mundo profano e a religião, por sua vez, um cosmo sagrado. Não podemos segmentar a religião da cultura, pois uma é substância e outra forma e a sua existência mútua fundamenta-se nessa intra-relação.

\section{A teologia africana como fruto do encontro entre religião e cultura africana: breve panorama}

Nesta seção, voltamos a discussão para o caso concreto da teologia africana, pois essa teologia comunga os dois elementos o da religião (o cristianismo) e o da cultura africana como fundamentais no fazer teológico desse continente. A análise utilizará as contribuições de Berger (sobre a cultura enquanto criação humana e esta, por sua vez, responsável por criar o mundo do homem e da religião como a encarregada da cosmificação sagrada desse mesmo mundo) e as contribuições de Tillich (a religião é a substância que permeia toda a cultura humana e a cultura é a responsável por dar forma 
à religião). O recorte contribui para uma análise da teologia africana e elabora enunciados teológicos, a partir de uma abordagem cultural e contextual da vivência religiosa situada na realidade da África subsaariana.

A teologia africana enquanto teologia contextual tem na cultura seu elemento primeiro e essencial. A cultura africana é a primeira identidade das religiões no continente. A teologia não despreza a vivência cultural das comunidades porque entende, acima de tudo, que essa vivência é influenciadora no fazer teológico - e a partir desse ponto é possível olhar para as manifestações culturais na religião e um fazer teológico africano comprometido com as raízes culturais.

\subsection{A Teologia Africana de acordo com a Declaração de Acra, (Gana), 1977}

Desde que a "boa nova" de Jesus Cristo ressoou nas florestas e savanas, e desde que muitos foram tocados, envolvidos ou perturbados no mais profundo de si mesmos por essa "mensagem", uma das questões com frequência levantadas diz respeito, precisamente, à compressão dessa "mensagem", de seu autor, das circunstâncias de sua transmissão e, finalmente, das consequências que a adesão a esse novo "caminho" leva consigo tanto no plano socioeconômico, sociopolítico, como no plano cultural e religioso (BIMWENYI-KWESHI apud GIBELLINE, 2012, p. 460).

A teologia africana se encontra inserida no seio das teologias contextuais. A igreja na África não ficou alheia às discussões teológicas inerentes ao seu contexto, pois compreendeu que o evangelho de Jesus Cristo precisaria ser interpretado no seio das comunidades originais. A teologia africana se apresenta como uma libertação da dependência epistemológica da teologia Ocidental. Toma-se a africanidade no fazer teológico, ou seja, a identidade cultural tradicional de ser dos homens e mulheres africanos como ponto de partida para a construção de uma teologia originariamente africana. O edifício teológico africano é responsável por interpretar a fé em Jesus Cristo para as comunidades do continente. Assim, ela precisa abandonar o "asilo epistemológico" de culturas e filosofias alheias (GIBELLINE, 2012, p. 463). Essa elaboração é comparada com o desenvolvimento da Teologia da Libertação na América Latina e a crítica ao eurocentrismo. ${ }^{3}$

A africanidade é uma proposta ideológica e cultural visando resgatar

3 Sobre esse assunto, cf. DUSSEL, Enrique. Filosofia da libertação. São Paulo: Edições LoyolaUNIMEP, 1982. 
o modo integral dos homens e das mulheres africanas de ser no mundo. Nessa proposta, a cultura, religiosidade e visão de mundo são tomadas como elementos para a construção de sua identidade. É determinante nas discussões teológicas contextuais advindas da África que se olhe para o africano como sujeito inserido no seu contexto local e a forma como este interpreta a fé cristã dentro de sua realidade cultural, religiosa, histórica, política e econômica, numa linguagem que lhe é característica e original. Observa-se que as culturas e religiões africanas são responsáveis por trazerem a existência das diversas sociedades espalhadas pelo continente. Nesse sentido, pode-se afirmar que a cultura/religião africana é criadora de significados e de modos de ser dos homens e mulheres na realidade histórica concreta de onde ela surge. Todas as instituições sociais em África são atravessadas pela cultura e religiosidade, pois estas são responsáveis pelo processo de cosmificação do mundo. É nesse sentido que as sociedades são frutos da cultura e da religião. A respeito da temática, Berger afirma:

A cultura consiste na totalidade dos produtos do homem. Alguns destes são materiais, outros não. O homem produz instrumentos de toda espécie imaginável, e por meio deles modifica o seu ambiente físico e verga a natureza à sua vontade. O homem produz também a linguagem e, sobre esse fundamento e por meio ele, um imponente edifício de símbolos que permeiam todos os aspectos de sua vida. Há boas razões para pensar que a produção e uma cultura não material foi sempre de par com a atividade do homem de modificar fisicamente o seu ambiente. Seja como for, a sociedade, naturalmente, nada mais é do que parte e parcela da cultura não material. A sociedade é aquele aspecto desta última que estrutura as incessantes relações do homem com seus semelhantes. Como apenas um elemento da cultura, a sociedade compartilha do caráter dessa como produto humano (BERGER, 1985, p. 22).

Assim, a cultura e a religião são vistas como sendo o subsolo que sustenta as sociedades africanas, bem como, as responsáveis pela identidade dos homens e mulheres no continente. É possível observar a vivência da cultura/religião se dissolvendo na sociedade e em algumas de suas instituições.

A sociedade é, portanto, não só resultado da cultura, mas uma condição necessária dela. A sociedade estrutura, distribui e coordena as atividades de construção do mundo desenvolvidas pelos homens. E só na sociedade os produtos dessas atividades podem durar. Compreender que a sociedade se radica 
na exteriorização do homem, isto é, que ela é um produto da atividade humana, é particularmente importante devido ao fato de que a sociedade se afigura ao bom senso como algo muito diferente, que independe da atividade humana e que participa da determinação inerte da natureza (BERGER, 1985, p. 24).

Dessa forma, torna-se indispensável descartar do fazer teológico as questões advindas das culturas e das sociedades africanas, pois estas são constitutivas de seu ser no mundo. Tanto a cultura como a religião são entendidas como empreendimentos de construção de um mundo humano. A vivência cultural e societária africana precisa ser tomada como elemento fundamental nas elaborações teológicas cristãs no continente. Assim sendo, os primeiros esforços em direção a uma elaboração sistemática e acadêmica de uma teologia africana aconteceram por volta dos anos de 1950, mais precisamente em 1956, em Paris, com o lançamento de uma obra literária Alcuni preti neri s'interrogano (Os padres negros se interrogam), contando com a participação de alguns jovens sacerdotes negros estudantes na Europa (GIBELLINI, 2010, p. 215).

Tendo em vista a criação da EATWOT - 1976, surgiu no continente africano a Associação Ecumênica dos Télogos Africanos - AOTA que ficou com a responsabilidade de dar continuidade às discussões da teologia contextual no continente, com o intuito de se pensar e elaborar uma teologia enraizada no território cultural negro-africano (BUJO e MUYA, 2012, p. 271). Nossa abordagem, acerca do paradigma epistemológico da teologia africana, é mediada pela análise da Declaração do encontro Pan-africano dos Teólogos do Terceiro Mundo, organizada em Acra (Gana), de 17 a 24 de dezembro do ano de 1977. A declaração de Acra é tida como o marco inicial do fazer teológico contextual africano, pois foi responsável por formular as bases pelas quais o edifício teológico africano foi construído e continua sendo edificado pela nova geração de teólogos e teólogas.

O encontro teológico em Acra (Gana) se configura como o esforço das comunidades cristãs africanas em interpretar a mensagem do evangelho de Jesus Cristo, a partir do seu contexto cultural e vivencial. $\mathrm{Na}$ introdução de Declaração de Acra (Gana), encontra-se escrito o seguinte:

Reunimo-nos em Acra devido à profunda solicitude que nutrimos pela fé em Jesus Cristo, em África. É esta fé no Senhor da história que nos fala concretamente, hoje. Quando louvamos alegremente o Senhor nosso Salvador e partilhamos os nossos problemas, temos consciência da presença muito real 
do Jesus incarnado, que nos conforta e nos dá esperança (BUJO e MUYA, 2012, p. 271).

As comunidades cristãs em África se entendem como parte do corpo místico de Jesus Cristo e são chamadas a pensar a fé no Senhor da história e autor da salvação da humanidade. A mensagem central do evangelho que se encarnou no seio da vivência humana convida os cristãos africanos a interpretar essa mensagem para o seu contexto concreto. $\mathrm{Na}$ introdução da Declaração de Acra (Gana), encontra-se ainda a afirmação dos teólogos africanos na relevância das Escrituras como o farol que ilumina o fazer teológico desde a África, bem como, sua solidariedade com todos os teólogos do Terceiro Mundo:

A palavra redentora do Senhor que liberta os cativos foi nosso farol. Isso não foi visível apenas no culto e no canto, mas também na dinâmica das sessões plenárias e dos grupos de trabalho. Afirmamos com vigor que é a mensagem do Antigo e do Novo Testamento que manifesta a audácia e o dinamismo do nosso diálogo de africanos cristãos com os Teólogos do Terceiro Mundo (BUJO e MUYA, 2012, p. 271).

Os teólogos africanos, no seu esforço em pensar a mensagem do evangelho de Jesus Cristo no contexto africano, defendem a necessidade de se manter uma solidariedade viva, criativa e ativa dentro do corpo místico de Cristo. Assim, o fazer teológico não se configura simplesmente como responsabilidade de uma elite de teólogos, mas um esforço hermenêutico empreendido pela comunidade de fé.

Uma das marcas do novo paradigma epistemológico da teologia contextual é a relevância da realidade concreta como primeiro ato do fazer teológico. Dessa forma, a Declaração de Acra descreve a realidade do contexto africano como o ponto de partida na elaboração da teologia africana. $\mathrm{Na}$ observação da realidade é que são levantadas as questões primordiais para o debate teológico. Quanto à realidade africana, a Declaração de Acra afirma o seguinte:

Damos graças a Deus pelo dinamismo e vitalidade das comunidades e das Igrejas cristãs em África. O rápido crescimento do povo de Deus em África, a originalidade da experiência africana da vida cristã no culto, na liturgia tipicamente africana, na leitura da Bíblia e na vida comunitária são para nós motivos de esperança e de confiança. Tomámos consciência que a unidade 
africana é a unidade do espírito e da alma, uma unidade indivisível na realidade histórica, que pode mesmo superar a incomunicabilidade geográfica. A nossa unidade é de uma participação ativa na plena comunhão de Deus: ela não se dissipa nas nuvens de um vago universalismo. Demo-nos conta também das ameaças que pesam sobre a unidade do nosso povo e lamentamos todos esses fatores que tendem a abalar a consciência da nossa unidade profundamente enraizada, quer que se trate do isolamento econômico, das manipulações do poder ou mesmo dos etilos de vida (BUJO e MUYA, 2012, p. 272).

A realidade vivencial é tomada como elemento essencial no esforço em pensar e interpretar a mensagem do evangelho de Jesus Cristo para a igreja na África. É no olhar crítico sobre a realidade contextual que questões como a problemática da unidade existente entre as comunidades africanas são introduzidas no debate teológico dentro do continente. A Declaração de Acra dá bastante ênfase na unidade existente entre as comunidades africanas, apesar das distâncias geográficas, culturais e linguísticas. Essa unidade é fundamentada no espírito africano que permeia todos os homens e mulheres no continente.

$\mathrm{O}$ autor Peter Berger entende que o mundo da cultura é fruto de uma construção do coletivo. Assim, podemos afirmar que a unidade das comunidades africanas é geradora de cultura. Berger (1985, p. 27) afirma: "[...] o mundo cultural é não só produzido coletivamente, como também permanece real em virtude do reconhecimento coletivo. Estar na cultura significa compartilhar com outros um mundo particular de objetividades". O mundo da cultura e o mundo da religião se encontram para formar uma sociedade una e singular, mesmo com os aspectos plurais pertinentes no cotidiano. Os teólogos reunidos em Acra defendiam a unidade dos povos africanos em face das constantes ameaças a esse princípio fundamental na sobrevivência dessas comunidades. O colonialismo foi responsável por abalar a unidade dos povos africanos durante muito tempo. Esse sistema colonial foi responsável por suscitar uma dominação e supremacia de uma minoria branca sobre uma maioria negra, pela força das armas, gerando problemas como o racismo e discriminação do homem e mulher africanos. Como diz a Declaração de Acra: "o racismo não é uma invenção africana, mas um assunto dos brancos” (BUJO e MUYA, 2012, p. 272).

Ao se voltar para o contexto específico das comunidades cristãs no continente africano, é possível observar qual é o caminho metodológico que a teologia contextual africana decide percorrer. Diferente da teologia contextual latino-americana que tem sua maior preocupação voltada para a análise da 
realidade de pobreza e de dominação político-econômica, a teologia africana se volta para além dessas mesmas questões para o problema da dominação cultural, da emancipação do africano. As questões ligadas à identidade cultural e à emancipação étnica são as que diferenciam a teologia contextual africana das outras formas de teologia contextuais.

O encontro de Acra (Gana) foi responsável por problematizar as questões ligadas à "etnicidade" na África, uma discussão reservada simplesmente para os etnólogos e antropólogos. Entretanto, os teólogos africanos foram responsáveis por introduzir a temática no campo da teologia sob o espectro da teologia contextual. A atitude é fruto da nova epistemologia da teologia contextual, que acredita que os problemas específicos do contexto influenciam o fazer teológico.

A "etnicidade", em África, como em qualquer outra parte do mundo, não pode ser confundida com o racismo. A "etnicidade" é um elemento positivo de qualquer sociedade humana. Contudo, ela pode também ser usada pelos poderes externos para servir os fins do racismo e causar a desunião, a guerra e o sofrimento (BUJO e MUYA, 2012, p. 271).

A preocupação da Declaração de Acra quanto à questão da "etnicidade" é legítima, pois esse tem sido um problema constante para as comunidades africanas. $\mathrm{O}$ racismo e as constantes guerras no continente são influenciados por questões étnicas seja internamente ou por forças externas que se aproveitam da situação. A teologia não precisa fechar seus olhos para estes questionamentos levantados pelo contexto, pois a mensagem do evangelho que se encarnou é a resposta.

A realidade africana exige que sejam inseparáveis a compreensão do amor e a sua expressão prática. O amor significa, por conseguinte, para nós, o ato coletivo de obediência de toda a comunidade humana ao Deus que está eternamente conosco. Na África contemporânea, não apenas esta compreensão do amor está a ser destruída pelos delitos de determinadas instituições nacionais ou companhias multinacionais, mas os delitos inerentes a estas instituições ou companhias causam também uma grande desunião, com frequência perpetuada pelo militarismo (BUJO e MUYA, 2012, p. 272).

Os cristãos do continente africano são compelidos a fazer um exercício hermenêutico da mensagem do evangelho, pois somente nele se encontram as palavras de vida eterna. No evangelho, o amor do Deus que atua na história 
humana se configura como assunto principal. O amor de Deus não é fundado em simples teorias ou ideologias humanas, mas antes é um amor fundado na prática e que se doa a si mesmo. Dessa forma, a teologia africana se preocupa com os problemas presentes na realidade histórica da igreja no continente e busca respondê-los à luz das Sagradas Escrituras. Na Declaração de Acra, encontra-se escrito o seguinte:

Os sofrimentos que são causados por esta situação provocaram milhares de mortos, sem falar das detenções e das situações penosas dos refugiados. É nossa convicção que a vontade de Deus para as Igrejas em África é não apenas que elas se opunham a todas as formas de opressão ou de sofrimento, mas ainda que elas evitem qualquer aliança direta ou indireta com as forças da opressão, por exemplo, reexaminando as suas carteiras de ações das multinacionais que favorecem a militarização sistemática dos governos, nos lugares onde atualmente predominam a luta pela sobrevivência, a supressão dos direitos humanos e a violação da dignidade humana (BUJO e MUYA, 2012, p. 272).

Na descrição da realidade africana, a Declaração de Acra mostra que o ponto de partida para o fazer teológico no continente é se voltar para a problematização do contexto específico da comunidade de fé. Depois de levantadas as questões inerentes à realidade, os esforços são voltados para a ida ao texto bíblico. É na leitura das Escrituras que o horizonte da realidade vivencial da comunidade se encontra com o horizonte do texto sagrado, desse encontro surge uma nova leitura da mensagem bíblica. A teologia contextual e a africana são, acima de tudo, um exercício hermenêutico realizado pela igreja de Cristo no mundo.

A Bíblia é a fonte fundamental da teologia africana, pois é nela que a mensagem do evangelho de Jesus Cristo se encontra presente. A missão do fazer teológico contextual no continente é interpretar essa mensagem para as comunidades cristãs. Não existe teologia africana, sem a observação central das Sagradas Escrituras. A Declaração de Acra descreve a relevância da Bíblia na teologia africana desta forma:

A Bíblia é a fonte fundamental da teologia africana, pois ela é o testemunho primordial da revelação de Deus em Jesus Cristo. Nenhuma teologia pode conservar a sua identidade cristã, à margem das Escrituras. Isto porque a Bíblia não é uma simples obra histórica a propósito do povo de Israel. Através de releitura destas Escrituras, no contexto social do nosso povo, em luta pela 
realização da sua humanidade, Deus fala-nos ao coração da nossa situação atormentada. Esta palavra divina não é uma proposição abstrata, mas um acontecimento nas nossas vidas, comprometendo-nos a continuar o combate pela nossa plena humanidade (BUJO e MUYA, 2012, p. 275).

No núcleo da teologia africana, se encontram as Sagradas Escrituras como tendo primazia no fazer teológico. O novo paradigma epistemológico não supervaloriza as ciências sociais em detrimento da Bíblia. No labor teológico contextual, as ciências sociais são usadas como referencial teórico para se analisar as questões inerentes à realidade específica do contexto, em nenhum momento elas se sobrepõem às Escrituras. Tal como defendido pela tradição cristã, a Bíblia é a regra de fé e prática no seio da teologia africana. O cristianismo africano é uma parte do cristianismo universal.

Outro elemento fundamental da teologia africana são as contribuições valiosas advindas das pesquisas antropológicas sobre as comunidades africanas, pois é por meio delas que as questões inerentes à vivência cultural dos homens e mulheres do continente são estudadas. Os teólogos em Acra se deram conta da relevância da antropologia para o pensamento teológico africano:

O destino da pessoa humana e o enquadramento da vida são dados fundamentais na vida do povo africano. O destino humano é o conflito dramático, entre a vida e a morte, que encontra o seu sentido na vitória da vida sobre a morte. Há uma unidade e continuidade, entre o destino da pessoa humana e o do cosmo. A vitória da vida na pessoa humana é também a vitória da vida no cosmo. A antropologia e a cosmologia africanas são otimistas. A salvação da pessoa humana, na teologia africana, é a salvação do universo, e no mistério da Encarnação, Cristo assume a totalidade do humano e a totalidade do cosmo (BUJO e MUYA, 2012, p. 276).

Há ainda outros elementos que são fundamentais para o labor teológico africano como é o caso das religiões tradicionais africanas (existe uma grande diversidade de manifestações religiosas no continente africano, estas se diferenciam de outros grupos religiosos ocidentais e asiáticos. Alguns elementos que perpassam as religiões tradicionais africanas são: a crença nos ancestrais como mediadores das benesses divinas para a humanidade; a participação na vida recebida de Deus ou união vital do cosmos; o culto aos antepassados; a experiência religiosa como prática familiar e comunitária; estes são alguns elementos presentes nas várias manifestações religiosas no continente), elas se mostram como fontes primordiais no estudo 
das experiências desses povos para com Deus. Desse modo, as religiões tradicionais africanas podem enriquecer a teologia e a espiritualidade cristã.

As outras fontes da teologia africana são assim definidas pela Declaração de Acra:

As experiências das formas culturais de via e das artes, a família alargada, a hospitalidade e a vida comunitária são a expressão de profundos sentimentos de amor e de atenção. As lutas pela transformação do sistema socioeconômico, as lutas contra o racismo, o sexismo e as outras formas de opressão econômica, política, social e cultural, devem ser sempre tidas em conta com seriedade como fontes de teologia (BUJO e MUYA, 2012, p. 276).

Uma das características fortes da teologia contextual africana é a sua criatividade, pois ela busca se reinventar de acordo com as novas questões que surgem no continente. A teologia contextual se apresenta como sendo um esforço das comunidades cristãs africanas em pensar e expor a mensagem central do cristianismo para a realidade contextual africana. Dessa forma, é preciso que o fazer teológico africano seja munido de criatividade, pois Deus em sua essência é criativo, e todo pensar teológico sobre Ele precisa ser criativo.

Entre o povo Ovimbundo se diz "Suku wa sovola viosi" (Deus criou tudo e todos). Essa afirmação mostra que existe entre os bantu o reconhecimento da criatividade como característica eterna de Deus. Essa afirmação, embora se referindo à realidade concreta e vivencial dessa etnia que estava diante de seus olhos, encontra correspondência no que assevera o teólogo Tillich (1987 p. 212) "a vida divina é criativa, atualizando-se em abundância inexaurível. A vida divina e a criatividade divina não são diferentes. Deus é criativo porque é Deus". A criação é o reflexo da liberdade de Deus, "tudo e todos" manifestam sua criatividade que se expressa em sua liberdade e destino, Deus "cria eternamente". Observa-se que o ato criativo de Deus é contínuo, não existe limite nem fim, Ele criou, continua criando e criará. Como descreve Tillich:

Já que a vida divina é essencialmente criativa, devem ser usados os três modos do tempo para simbolizá-la. Deus criou o mundo, é criativo no momento presente e plenificará criativamente seu telos. Podemos, devemos falar em criação originante, criação mantenedora, e criação diretiva. Isso significa que não só a preservação do mundo, mas também a providencia estão incluídas na doutrina da criatividade divina (TILLICH, 1987, p. 213). 
Atendendo a preposição citada, acerca da criatividade de Deus, torna-se indispensável, para o fazer teológico africano, a criatividade: uma característica essencial em suas elaborações teológicas, bem como na sua prática eclesial. A teologia contextual no continente africano precisa pensar a fé cristã atendendo os seguintes aspectos: (1) olhar para todo o desenvolvimento histórico e teológico do cristianismo ao longo dos tempos, e de forma específica para o passado da igreja em África; (2) pensar a fé no presente vivencial das comunidades cristãs no continente, dessa forma a teologia se torna apta para responder aos novos questionamentos levantados pela realidade africana; (3) faz-se necessário também perspectivar o futuro da Igreja, bem como do fazer teológico e de suas novas formulações. Nesse sentido, a teologia contextual africana é viva e criativa, porque não se preocupa simplesmente com questionamentos retrógrados, mas se propõe pensar as experiências religiosas cristãs no presente e mantém ao mesmo tempo os olhos fitos no futuro da Igreja e de suas formulações teológicas.

O historiador Rosino Gibelline descreve a Declaração de Acra como sendo os primeiros passos em direção a uma elaboração teológica originariamente africana. $\mathrm{O}$ autor a relata da seguinte maneira:

A Declaração final de Acra (EATWOT II) expressou um dupla convicção: a) "A teologia africana deve ser uma teologia contextual, que corresponda ao contexto da vida e da cultura em que vive o povo. [...] A contextualização significa que a teologia deverá tratar da libertação de nosso povo da escravidão cultural"; mas ao mesmo tempo b) realizou a ligação entre dimensão cultural e dimensão socioeconômica: "Uma vez que a opressão não se encontra somente na cultura, mas também nas estruturas políticas e econômicas e nos meios de comunicação dominantes, a teologia africana deve ser também uma teologia da libertação. O acento posto na libertação pela teologia africana a vincula às outras teologias do Terceiro Mundo". Em Acra foram claramente identificadas duas dimensões da teologia do Terceiro Mundo, que haveriam de ser sucessivamente retomadas e desenvolvidas: teologia contextual e teologia da libertação (GIBELLINE, 2012, p. 451).

Com a Declaração de Acra estavam definidas as bases para o debate teológico no continente. Nos resultados do encontro, em Acra, transparecem também as contribuições advindas das comunidades cristãs na África para o corpo místico de Cristo no mundo.

A teologia não se encontra condenada a formular questões ultrapassadas ou irrelevantes, antes ela é dinâmica e geradora de novas 
formulações, pois sua preocupação se fundamenta numa tríplice existência temporal: ela fala do agir de Deus no ceio da humanidade no tempo passado; fala do agir presente de Deus na realidade histórica concreta; e tem suas esperanças escatológicas ancoradas no agir criativo eterno de Deus. É dessa forma que a teologia cristã se encontra no "caminho da vida", e sempre caminhando no seguimento dos rastros do Deus que se faz presente na História da humanidade.

\section{Considerações finais}

Toda a teologia nasce de algum lugar e não de lugar algum, o que leva a dizer que ela é influenciada, se não determinada, pelo contexto no qual evoluirá. Como afirmou o teólogo alemão Schleiermacher, nunca houve uma mensagem "pura", "supracultural" e "supra-histórica"; ou seja: o contexto do leitor influencia na sua interpretação da mensagem do texto (SCHMIDT, 2013, p. 29). O que, na verdade, não é diferente no paradigma da teologia contextual, marcado por vários fatores (sejam eles históricos, culturais, políticos e religiosos) e elementos que influenciam radicalmente o pensamento e o fazer teológico. Tais influências se estendem, sobretudo, na práxis diária da igreja de Cristo no mundo e criam uma identidade única e singular em culturas locais resistentes e sobreviventes diante da colonização e da eugenia europeia.

O paradigma epistemológico da teologia contextual se configura como fruto da ruptura com o método teológico tradicional ocidental para dar voz à sobrevivência das tradições culturais e religiosas africanas em novos discursos imbuídos de originalidade. A nova epistemologia teológica nasce do contexto e prioriza as questões advindas da realidade histórica como fontes para o pensamento teológico no continente. O resgate se assemelha com outros processos de libertação no terceiro mundo e dialoga com suas fontes, tanto coloniais, quanto originais.

O artigo buscou, portanto, traçar um breve panorama da teologia contextual africana a partir dos registros da Declaração dos teólogos africanos de Acra, pensada e apresentada pelos instrumentais de Peter Berger e Paul Tillich - dois teóricos consagrados no estudo social e filosófico das religiões e da cultura. Foi observado que a teologia contextual é percebida e trabalhada como um esforço hermenêutico com o qual as comunidades cristãs em África precisam fazer para interpretar a essência da mensagem central do cristianismo no seu contexto específico. 


\section{Referências}

ALTUNA, Raul Ruiz De Asúa. Cultura Tradicional Bantu. Lisboa: Paulinas, 2006.

BAUR, John. 2000 anos de cristianismo em África: uma história da igreja africana. Prior Velho: Paulinas, 2014.

BERGER, Peter L. O dossel sagrado: elementos para uma teoria sociológica da religião. São Paulo: Paulus, 1985.

BOSCH, David J. Missão transformadora: mudanças de paradigma na teologia da missão. São Leopoldo, RS: EST, Sinodal, 2002.

BUJO, Bénézet e MUYA, Juvénal. "Alexis Kagame: os traços de uma teologia africana." In: Teologia africana no século XXI: algumas figuras, v. 2. Lisboa: Paulinas, 2012, p. 11-43.

BUJO, Bénézet e MUYA, Juvénal. "Bénézete Bujo: declaração do encontro Pan-Africano dos teólogos do terceiro mundo (Acra, Gana)", 17-24 dez. 1977. In: Teologia africana no século XXI: algumas figuras, v. 2. Lisboa: Paulinas, 2012, p. 271-276.

BUJO, Bénézet e MUYA, Juvénal. "Bénézete Bujo: o despertar de um pensamento sistemático e autêntico africano." In: Teologia africana no século XXI: algumas figuras, v. 1. Lisboa: Paulinas, 2012, p. 97-135.

ELIADE, Mircea. O Sagrado e o Profano. São Paulo: Martins Fontes, 2001.

GIBELline, Rosino. A teologia do século XX, 3. ed. São Paulo: Edições Loyola, 2012.

GIBELLINE, Rosino. Breve história da teologia do século XX. Aparecida, SP: Editora Santuário, 2010.

OTTO, Rudolf. O Sagrado: aspectos irracionais na noção do divino e sua relação com o racional. São Leopoldo: Sinodal/EST; Petrópolis: Vozes, 2007.

PIAZZA, Waldomiro Octavio. Introdução à fenomenologia religiosa. Petrópolis: Vozes, 1983.

SANCHES, Sidney. A teologia evangélica contextual. São Paulo: Editora Reflexão, 2010.

SCHMIDT, Lawrance K. Hermenêutica. Petrópolis: Vozes, 2013.

TILLICH, Paul. Dynamics of Faith. New York: Harper, 2001.

TILLICH, Paul. Teologia da cultura. São Paulo: Fonte Editorial, 2009.

TILLICH, Paul. Teologia sistemática. São Leopoldo: Sinodal, 1987.

YAKULEINGE, Gaudêncio Félix. Uma teologia cristã desde os Ritos de Ovakwanyama. Lisboa: Paulus, 2012.

Submetido em: 5-12-2018

Aceito em: 6-12-2018 